\title{
Identification of Surface Proteins Mediating Adherence of CD11/CD18-deficient Lymphoblastoid Cells to Cultured Human Endothelium
}

\author{
Barbara R. Schwartz," Elizabeth A. Wayner, Timothy M. Carlos," Hans D. Ochs, ${ }^{\ddagger}$ and John M. Harlan \\ Departments of "Medicine and ${ }^{\ddagger}$ Pediatrics, University of Washington, Seattle, Washington 98195 ; \\ and ${ }^{\S}$ Oncogen, Seattle, Washington 98121
}

\begin{abstract}
Patients with the severe form of leukocyte adhesion deficiency syndrome do not express the CD11/CD18 adhesion complex on any of their leukocytes. Nevertheless, their lymphocytes, unlike their phagocytes, emigrate to extravascular sites of inflammation, demonstrating that surface proteins other than CD11/CD18 can mediate lymphocyte adherence to endothelium. Using a B-lymphoblastoid cell line (B-LCL) established from a CD11/CD18-deficient patient and cultured human umbilical vein endothelial cells (HEC), we investigated the CD11/CD18-independent mechanism(s) of lymphocyte adherence to endothelium. Monoclonal antibodies directed to the $\alpha_{4}$ polypeptide (CD49d) and the $\beta_{1}$ polypeptide (CD29) of the lymphocyte VLA-4 integrin receptor (CD49d/CD29), and to vascular cell adhesion molecule-1 (VCAM-1) on the endothelial cell significantly inhibited the adherence of the CD11/ CD18-deficient B-LCL to untreated HEC and to HEC treated with recombinant human tumor necrosis factor-alpha. We suggest that the interaction of the lymphocyte receptor VLA-4 with the endothelial ligand VCAM-1 induced by cytokines at sites of inflammation or immune reaction represents a CD11/ CD18-independent pathway of lymphocyte emigration. ( $J$. Clin. Invest. 1990. 85:2019-2022.) VLA-4 • VCAM-1 • leukocyte adhesion deficiency
\end{abstract}

\section{Introduction}

Leukocyte adhesion deficiency (LAD) ${ }^{1}$ is the syndrome produced by congenital absence or deficiency of leukocyte $\beta_{2}$ integrin receptor complex CD11/CD18 (1). This syndrome is characterized by delayed separation of the umbilical cord, recurrent bacterial infections, and persistent leukocytosis. These clinical

Address reprint requests to Barbara Schwartz, M.S., Division of Hematology ZA-34, Harborview Medical Center, 325 Ninth Avenue, Seattle, WA 98104.

Received for publication 26 December 1989 and in revised form 5 March 1990.

1. Abbreviations used in this paper: B-LCL, B-lymphoblastoid cell line; HEC, human umbilical vein endothelial cells; ICAM, intercellular adhesion molecule; LAD, leukocyte adhesion deficiency; rhTNF, recombinant human tumor necrosis factor-alpha; VCAM-1, vascular cell adhesion molecule 1 .

J. Clin. Invest.

(c) The American Society for Clinical Investigation, Inc. 0021-9738/90/06/2019/04 \$2.00

Volume 85, June 1990, 2019-2022 manifestations of LAD result from a profound defect in phagocyte emigration as evidenced by absence of pus formation at sites of inflammation and infection and failure of phagocytes to emigrate to skin windows or chambers (2). The defect in emigration appears to result from inability of LAD phagocytes to bind to endothelium at sites of inflammation $(3,4)$.

Although lymphocytes in LAD syndrome are also deficient in CD11/CD18, lymphocyte traffic appears to be normal even in severely affected patients. Biopsies or surgical specimens of sites of inflammation reveal lymphocytes in extravascular tissues (5). Moreover, patients with LAD syndrome exhibit intact delayed-type hypersensitivity responses and do not develop infections characteristic of impaired cell-mediated immunity (5). These observations suggest that there is a CD11/CD18-independent mechanism for lymphocyte adhesion to endothelium at sites of inflammation or immune reaction. Consistent with this, B-lymphoblastoid cell lines (B-LCL) established from LAD patients, and normal B-LCL treated with MAbs to CD11/CD18, adhere to unstimulated cultured human umbilical vein endothelial cells (HEC). Notably, B-LCL from LAD patients increase their adherence to cytokine-stimulated HEC to the same extent as B-LCL from normal donors (6).

Using a B-LCL from a patient with LAD syndrome (7) and MAbs that recognize functional epitopes of cell surface proteins on lymphocytes and on endothelial cells, we investigated CD11/CD18-independent adherence of lymphocytes to HEC. In this study we demonstrate that the adherence of CD11/ CD18-deficient B-LCL to untreated HEC and to cytokinetreated HEC involves the integrin receptor VLA-4 (CD49d/ CD29) on the lymphocytes $(8,9)$ and an endothelial cell protein, vascular cell adhesion molecule 1 (VCAM-1) (Carlos, T. M., B. R. Schwartz, N. L. Kovach, E. Yee, and J. M. Harlan, manuscript submitted for publication) (10). These adhesion proteins may play an important role in lymphocyte emigration to tissue at sites of inflammation or immune reaction.

\section{Methods}

Cell culture. HEC were prepared as described (11) and grown in RPMI 1640 medium (RPMI) (Whittaker Bioproducts, Inc., Walkersville, MD) containing 10\% calf serum (Flow Laboratories, McLean, VA) and $10 \%$ adult bovine serum (HyClone Laboratories, Logan, UT), with the addition of $90 \mu \mathrm{g} / \mathrm{ml}$ heparin (Sigma Chemical Co., St. Louis, MO), sodium pyruvate, nonessential amino acids, $10 \mathrm{mM}$ Hepes, and penicillin-streptomycin-Fungizone (Gibco Laboratories, Grand Island, NY) and endothelial cell growth factor prepared from bovine brain (12).

The EBV-transformed B-LCL was established from peripheral blood cells isolated from a patient with complete deficiency of surface 
CD11/CD18 (patient 1 in reference 7). The cells were maintained in RPMI 1640 medium containing 10\% FBS (HyClone Laboratories) with glutamine, sodium pyruvate, and antibiotics.

Monoclonal antibodies. Monoclonal antibody $\mathrm{P} 4 \mathrm{C} 2$ is a murine $\mathrm{IgG}_{3}$ antibody that binds to an epitope on the $\alpha_{4}$ polypeptide (CD49d) of integrin receptor VLA-4 (CD49d/CD29). Monoclonal antibody P3E3 is a murine $\mathrm{IgG}_{3}$ antibody that binds to a different epitope also on CD49d. Monoclonal antibodies P4C2 and P3E3 are both effective in inhibiting T-lymphocyte adherence to fibronectin (9). Monoclonal antibody $\mathrm{P4C10}$ is a murine $\mathrm{IgG}_{1}$ antibody that recognizes the $\beta$-chain polypeptide (CD29) common to the $\beta_{1}$ integrin receptors (Wayner, E. A., manuscript in preparation). Monoclonal antibody 4B9 is a murine $\operatorname{IgG}_{1}$ antibody that binds to a functional epitope on VCAM-1 (Carlos, T. M., B. R. Schwartz, N. L. Kovach, E. Yee, and J. M. Harlan, manuscript submitted for publication). Monoclonal antibody $\mathrm{RR} 1 / 1$ is a murine $\mathrm{IgG}_{1}$ antibody that recognizes ICAM-1 (CD54)(13) and was a generous gift of Dr. Robert Rothlein (Boehringer-Ingleheim, Inc., Ridgefield, CT). Monoclonal antibody 60.3 is a murine $\mathrm{IgG}_{2 \mathrm{a}}$ antibody that recognizes the common beta-chain (CD18) of the $\beta_{2}$ integrin receptor CD11/CD18 (7). Monoclonal antibodies 4B9, RR1/1 and 60.3 were used as purified immunoglobulins. Monoclonal antibodies P4C2, P3E3, and P4C10 were used as hybridoma culture supernatant medium. The hybridoma medium consisted of RPMI 1640 containing 10\% FBS (HyClone Laboratories).

Adherence assay. Adherence experiments were performed in 48well clusters (Costar, Cambridge, MA). The B-LCL from the LAD patient were labeled with ${ }^{51} \mathrm{Cr}$ as previously described (14), washed, and resuspended in RPMI containing $2 \%$ FBS at $2 \times 10^{6} / \mathrm{ml}$. Before assay the ${ }^{51} \mathrm{Cr}$-labeled cells were incubated for $20 \mathrm{~min}$ at room temperature with an equal volume of hybridoma culture medium alone; hybridoma culture supernatant medium containing MAb P4C2, P3E3, or P4C10; or purified MAb $60.3(40 \mu \mathrm{g} / \mathrm{ml})$. Human umbilical vein endothelial cells were pretreated with growth medium alone or medium containing recombinant human tumor necrosis factor-alpha (rhTNF) $\left(10 \mathrm{ng} / \mathrm{ml}\right.$ at $37^{\circ} \mathrm{C}$ for $\left.19 \mathrm{~h}\right)$. Before assay HEC were incubated for $20 \mathrm{~min}$ at $37^{\circ} \mathrm{C}$ with $150 \mu \mathrm{l}$ of RPMI-2\% calf serum or the same medium containing MAb 4B9 or RR1/1 $(2.5 \mu \mathrm{g} / \mathrm{ml})$. These concentrations of MAb were determined to be saturating by ELISA. At the time of assay, $150 \mu \mathrm{l}$ of the ${ }^{51} \mathrm{Cr}$-labeled B-LCL were added to the wells. After a 20 -min incubation at $37^{\circ} \mathrm{C},{ }^{51} \mathrm{Cr}$-labeled nonadherent cells were decanted and the monolayer was washed once with medium. The nonadherent cells and wash were combined. Adherent cells were lysed with $1 \mathrm{~N} \mathrm{NH}_{4} \mathrm{OH}$. The lysate was then harvested and combined with one wash of $1 \mathrm{~N} \mathrm{NH}_{4} \mathrm{OH}$. Radioactivity was determined in a gamma spectrophotometer (Micromedic Systems, Horsham, PA). Percent adherence was calculated as adherent cpm/(adherent + nonadherent $\mathrm{cpm}) \times 100 \%$ for each well. Results are expressed as mean $\pm \operatorname{SEM}$ of $(n)$ experiments.

Flow cytometry and ELISA. Expression of VLA-4 (CD49d/CD29), CD11/CD18, VCAM-1, and ICAM-1 on cells was examined by flow cytometry for leukocytes and by ELISA for HEC. Bindng of MAbs to B-LCL was detected by fluorescein-isothiocyanate goat anti-mouse immunoglobulin second antibody (Tago, Inc., Burlingame, CA) on an EPICS 750 cell sorter (Coulter Electronics, Hialeah, FL), as previously described (15). For ELISA assay, HEC were plated in 96-well plates (Costar) and treated with culture medium or medium containing 10 $\mathrm{ng} / \mathrm{ml}$ rhTNF at $37^{\circ} \mathrm{C}$ for $19 \mathrm{~h}$. The HEC were washed and incubated at $37^{\circ} \mathrm{C}$ for $1 \mathrm{~h}$ with: hybridoma culture medium alone; hybridoma supernatant medium containing MAb P4C2, P3E3, or P4C10; RPMI-2\% calf serum alone; or RPMI-2\% calf serum containing MAb 4B9 $(2.5 \mu \mathrm{g} / \mathrm{ml}), \mathrm{RR} 1 / 1(2.5 \mu \mathrm{g} / \mathrm{ml})$, or $60.3(20 \mu \mathrm{g} / \mathrm{ml})$. After washing, the cells were fixed with freshly diluted $0.5 \%$ glutaraldehyde. The MAb bound was quantitated by binding of peroxidase-conjugated goat anti-mouse immunoglobulin (Tago, Inc.). Peroxidase activity of the bound second antibody was determined with addition of $o$-phenylenediamine $(1 \mathrm{mg} / \mathrm{ml})$ and $0.003 \%$ hydrogen peroxide (Sigma Chemical Co.) in $0.1 \mathrm{M}$ sodium citrate $\mathrm{pH}$ 4.5. Absorbance at $492 \mathrm{~nm}\left(\mathrm{~A}_{492}\right)$ was measured on a Titertek Multiskan MCC/ 340 (Flow Laboratories).
Reagents. Recombinant human TNF was a gift of Biogen (Cambridge, MA). The NS-1F myeloma subclone used in the fusion resulting in MAb 4B9 was a gift of Dr. Charles Hart (ZymoGenetics, Seattle, WA).

\section{Results}

Table I summarizes the effect of several MAbs to lymphocyte and endothelial cell surface proteins on the adherence of CD1 1/CD18-deficient B-LCL to untreated and rhTNF-treated HEC. The CD49d MAb P4C2 (anti- $\alpha_{4}$ ) markedly inhibited the adherence of CD11/CD18-deficient B-LCL to both untreated and rhTNF-treated HEC. Monoclonal antibody P3E3, directed to a different epitope on CD49d, also inhibited adherence to HEC, but to a much lesser extent than MAb P4C2. The anti-VCAM-1 MAb 4B9 partially inhibited the adherence of CD11/CD18-deficient B-LCL to unstimulated HEC and greatly inhibited adherence to rhTNF-stimulated HEC. The inhibitory effect of MAb 4B9 was additive to that produced by MAb P3E3 but not to MAb P4C2. The inhibitory effect of MAb P4C2 alone was equal to that produced by the combination of MAbs P3E3 and 4B9. As expected, the anti-ICAM-1 MAb RR1/1 and the CD18 MAb 60.3 did not inhibit the adherence of CD1 1/CD18-deficient B-LCL to either untreated or rhTNF-treated HEC (data not shown).

The CD29 MAb P4C10 also inhibited adherence of the CD11/CD18-deficient B-LCL to untreated and rhTNF-treated HEC. Adherence to untreated HEC was $31 \pm 3 \%$ with control hybridoma medium vs. $17 \pm 3 \%$ with MAb P4C10 $(P<0.005)$, and adherence to rhTNF-treated HEC was $61 \pm 3 \%$ in control hybridoma medium vs. $35 \pm 6 \%$ with MAb P4C10 $(P<0.005)$ (means \pm SEM of four experiments).

Table II reports the binding of the various MAbs to CD11/ CD18-deficient B-LCL and to untreated and rhTNF-treated HEC. The CD29 MAb P4C10 and the anti-ICAM-1 MAb RR1/1 bound to untreated and rhTNF-treated HEC. The anti-VCAM-1 MAb 4B9 bound minimally to untreated HEC, but significantly to rhTNF-treated HEC. The CD49d MAbs P4C2 and P3E3, and the CD18 MAb 60.3 did not bind to

Table I. Effect of CD49d (Anti- $\left.\alpha_{4}\right)$ and Anti-VCAM-1 MAbs on Adherence of CD11/CD18-deficient B-LCL to HEC

\begin{tabular}{lcc}
\hline \multicolumn{1}{c}{ MAb } & \multicolumn{2}{c}{ Percent adherence } \\
\cline { 2 - 3 } & Untreated HEC & rhTNF-treated HEC \\
\hline None (7) & $17 \pm 2$ & $49 \pm 3$ \\
4B9 (anti-VCAM-1) (7) & $9 \pm 1^{*}$ & $17 \pm 2^{*}$ \\
P3E3 (CD49d, anti- $\left.\alpha_{4}\right)(4)$ & $11 \pm 1^{*}$ & $41 \pm 2$ \\
P3E3 + 4B9 (4) & $5 \pm 1^{* \neq}$ & $7 \pm 1^{* \neq}$ \\
P4C2 (CD49d, anti- $\left.\alpha_{4}\right)(7)$ & $5 \pm 1^{*}$ & $6 \pm 1^{*}$ \\
P4C2 + 4B9 (3) & $6 \pm 1^{*}$ & $7 \pm 1^{*}$ \\
\end{tabular}

CD11/CD18-deficient B-LCL were pretreated with MAb P3E3 or P4C2 (1:1 dilution of hybridoma supernatant medium) at room temperature for $20 \mathrm{~min}$. Untreated or rhTNF-treated $(10 \mathrm{ng} / \mathrm{ml}$ for $19 \mathrm{~h})$ HEC were pretreated with $\mathrm{MAb} 4 \mathrm{~B} 9(2.5 \mu \mathrm{g} / \mathrm{ml})$ for $20 \mathrm{~min}$ at $37^{\circ} \mathrm{C}$. Percent adherence was determined after a 20 -min incubation at $37^{\circ} \mathrm{C}$. Values represent the means $\pm \operatorname{SEM}$ of $(n)$ separate experiments. * $P<0.01$ by Student's two-tailed $t$ test, compared to no MAb. ${ }^{\ddagger} P<0.01$ by Student's two-tailed $t$ test, compared to the same MAb in the absence of MAb 4B9. 
Table II. Expression of Adherence Proteins on CD11/CD18-deficient B-LCL and HEC

\begin{tabular}{lccc}
\hline & & \multicolumn{2}{c}{ Endothelial cells $^{\ddagger}$} \\
\cline { 3 - 4 } \multicolumn{1}{c}{ MAb } & $\begin{array}{c}\text { B-LCL* } \\
\text { Mean peak }\end{array}$ & Untreated & $\begin{array}{c}\text { rhTNF- } \\
\text { treated }\end{array}$ \\
\hline P4C2 (CD49d, anti- $\left.\alpha_{4}\right)$ & 53 & 0 & 0 \\
P3E3 (CD49d, anti- $\left.\alpha_{4}\right)$ & 65 & 0 & 0 \\
P4C10 (CD29, anti- $\left.\beta_{1}\right)$ & 44 & $0.24 \pm 0.05$ & $0.27 \pm 0.05$ \\
60.3 (CD18, anti- $\left.\beta_{2}\right)$ & 0 & 0 & 0 \\
4B9 (anti-VCAM-1) & 0 & $0.06 \pm 0.02$ & $0.26 \pm 0.05$ \\
RR1/1(CD54, anti-ICAM-1) & 58 & $0.21 \pm 0.03$ & $0.37 \pm 0.03$ \\
\hline
\end{tabular}

* Binding of MAb to B-LCL was assessed by flow cytometry as described in Methods. Values for net mean peak fluorescence were calculated by subtracting values obtained with FITC-conjugated second antibody alone and represent the average of two determinations. ${ }^{\ddagger}$ Binding of MAb to untreated or rhTNF-treated $(10 \mathrm{ng} / \mathrm{ml}$ for $18 \mathrm{~h})$ HEC was assessed by ELISA as described in Methods. Net $\mathrm{A}_{492}$ was calculated by subtracting the $\mathrm{A}_{492}$ of HEC that were tested with peroxidase-conjugated second antibody only. Values represent the means \pm SEM of three experiments.

HEC. The CD11/CD18-deficient B-LCL bound MAbs P4C2, P3E3, P4C10, and RR1/1, but did not bind MAbs 60.3 or 4B9.

\section{Discussion}

Previous studies have established the importance of lymphocyte CD11a/CD18 (LFA-1) and endothelial cell ICAM-1 or ICAM-2 in basal and stimulated lymphocyte adherence to unstimulated HEC (16-18). Haskard et al., however, reported that binding of peripheral blood T-lymphocytes (16) or CD1 1/CD18-deficient B-LCL (6) to cytokine-treated HEC was independent of CD11/CD18. This report demonstrates the involvement of the lymphocyte VLA-4 integrin receptor in the CD11/CD18-independent mechanism of CD11/CD18-deficient B-LCL adherence to untreated and rhTNF-treated HEC and the involvement of endothelial VCAM- 1 in the ICAM-independent adherence of B-LCL to rhTNF-treated HEC.

The CD49d MAbs P4C2 and P3E3 (anti- $\alpha_{4}$ ) (9) and the CD29 MAb P4C10 (anti- $\beta_{1}$; Wayner, E. A., manuscript in preparation) have recently been shown to inhibit lymphocyte binding to fibronectin. Both MAb P4C2 and MAb P4C10 significantly inhibited adherence of CD11/CD18-deficient B-LCL to untreated and rhTNF-treated HEC. Interestingly, inhibition produced by the CD49d MAb P3E3 was considerably less than that obtained with the CD49d MAb P4C2, although the binding of MAb P3E3 to B-LCL was greater. This result indicates that the epitope on CD49d recognized by MAb P4C2 participates in lymphocyte adhesion to HEC to a greater extent than the epitope recognized by MAb P3E3, and suggests that the binding site on VLA-4 for VCAM-1 is distinct from the binding site for fibronectin recognized by MAb P3E3. In keeping with this hypothesis, we have found that MAb P3E3 does not inhibit the binding of lymphocytic cell lines to VCAM-1-transfected CHO cells, whereas MAb P4C2 does (Schwartz, B. R., J. M. Harlan, and E. Wayner, unpublished observations).

Lymphocyte adherence to HEC has previously been shown to involve the endothelial proteins ICAM-1 (17) and ICAM-2 (18). Recently, using an expression-cloning technique, Osborn et al. identified a new endothelial ligand, VCAM-1, a rhTNFand rhIL-1-inducible endothelial cell surface protein that binds lymphocytic cell lines (10). Independently, we produced $\mathrm{MAb} 4 \mathrm{~B} 9$ that binds to a $100-\mathrm{kD}$ protein induced on rhTNFtreated HEC and inhibits the adherence of peripheral blood lymphocytes to rhTNF-treated HEC (Carlos, T. M., B. R. Schwartz, N. L. Kovach, E. Yee, and J. M. Harlan, manuscript submitted). Monoclonal antibody 4B9 binds to $\mathrm{CHO}$ cells transfected with VCAM-1 cDNA and also inhibits the binding of lymphocytic cell lines to VCAM-1-transfected CHO cells, thereby demonstrating that VCAM-1 is the endothelial antigen recognized by MAb 4B9 (Schwartz, B. R., J. M. Harlan, and $\mathrm{E}$. Wayner, unpublished observations).

The marked inhibition of CD11/CD18-deficient B-LCL binding to rhTNF-treated HEC produced by MAb 4B9 indicates that VCAM-1 is an important inducible endothelial ligand for lymphocytes. MAb 4B9 also significantly reduced CD11/CD18-deficient B-LCL adherence to untreated HUVE. Consistent with this observation, low levels of VCAM-1 were detected on untreated HEC by ELISA. This minimal basal expression of VCAM-1 may reflect residual expression after activation by IL-1 or TNF generated by contaminating leukocytes in primary passage.

Both the CD49d MAb P4C2 and the CD29 MAb P4C10 inhibited the adherence of CD11/CD18-deficient B-LCL to untreated and rhTNF-treated HEC and no additive effect was observed with the combination of MAb P4C2 and MAb 4B9. From these results we conclude that VCAM-1 is a ligand for VLA-4 (CD49d/CD29). The greater inhibition observed with MAb P4C2 compared to MAb 4B9 most likely results from its ability to inhibit lymphocyte adherence to fibronectin exposed in cultured HEC as well as binding to VCAM-1. This possibility is supported by the observation that MAb P3E3, which inhibits binding to fibronectin but not VCAM-1, and MAb 4B9 were additive and that the combination of MAb P3E3 and MAb 4B9 was then equal to MAb P4C2.

The VLA-4 (CD49d/CD29) receptor has previously been shown to be involved in cell-cell interactions (19) including cytolytic $T$ cell adhesion to B cell targets $(20,21)$, the interaction between helper and suppressor cells (22), and homotypic lymphocyte aggregation (23). Our results suggest that the VLA-4 receptor also mediates lymphocyte adherence to HEC through an interaction with endothelial VCAM-1. We propose that the interaction of lymphocyte VLA- 4 with the endothelial cell VCAM-1 ligand induced by cytokines at sites of inflammation may be an important mechanism by which CD11/ CD18-deficient lymphocytes are able to emigrate to tissue and thereby maintain cell-mediated immunity in patients with LAD syndrome.

\section{Acknowledgments}

We thank Dr. Charles Hart for the gift of the NS-1F cell line and Dee Ann Curtis for her advice in developing monoclonal antibodies. We thank Dr. Roy Lobb, Biogen, Inc. for providing VCAM-1-transfected CHO cells used in our preliminary studies characterizing MAbs $\mathrm{P} 4 \mathrm{C} 2$, P3E3, and 4B9.

This work was supported by U. S. Public Health Service grants HL18645 (J. M. Harlan) and IA07073 (H. D. Ochs). A portion of this work was conducted in the Clinical Research Center of the University of Washington and supported by MH grant RR37. J. M. Harlan is an Established Investigator of the American Heart Association. T. M. Carlos is the recipient of a Clinician Scientist Award of the American Heart Association. 
Note added in proof. Using cell lines transfected with CD49d and with VCAM-1, Elices et al. (24) demonstrated that CD49d/CD29 (VLA-4) is the leukocyte receptor for VCAM-1.

\section{References}

1. Anderson, D. C., and T. A. Springer. 1987. Leukoycte adhesion deficiency: an inherited defect in the Mac-1, LFA-1, and p150, 95 glycoproteins. Annu. Rev. Med. 38:175-194.

2. Bowen, T. J., H. D. Ochs, L. C. Altman, T. H. Price, D. E. Van Epps, D. L. Brautigan, R. E. Rosin, W. D. Perkins, B. M. Babior, S. J. Klebanoff, and R. J. Wedgwood. 1982. Severe recurrent bacterial infections associated with defective adherence and chemotaxis in two patients with neutrophils deficient in a cell-associated glycoprotein. $J$. Pediatr. 101:932-940.

3. Harlan, J. M., P. D. Killen, F. M. Senecal, B. R. Schwartz, E. K. Yee, R. F. Taylor, P. G. Beatty, T. H. Price, and H. D. Ochs. 1985. The role of neutrophil membrane glycoprotein GP-150 in neutrophil adherence to endothelium in vitro. Blood. 66:167-178.

4. Arfors, K.-E., C. Lundberg, L. Lindbom, K. Lundberg, P. G. Beatty, and J. M. Harlan. 1987. A monoclonal antibody to the membrane glycoprotein complex CD18 inhibits polymorphonuclear leukocyte accumulation and plasma leakage in vivo. Blood. 69:338-340.

5. Anderson, D. C., F. C. Schmalsteig, M. J. Finegold, B. J. Hughes, R. Rothlein, L. J. Miller, S. Kohl, M. F. Tosi, R. L. Jacobs, T. C. Waldrop, A. S. Goldman, W. T. Shearer, and T. A. Springer. 1985. The severe and moderate phenotypes of heritable Mac-1, LFA-1 deficiency: their quantitative definition and relation to leukocyte dysfunction and clinical features. J. Infect. Dis. 152:668-689.

6. Haskard, D. O., S. Strobel, M. Thornhill, C. Pitzalis, and R. J. Levinsky. 1989. Mechanisms of lymphocyte adhesion to endothelial cells: studies using a LFA-1-deficient cell line. Immunology. 66:111116.

7. Beatty, P. G., J. M. Harlan, H. Rosen, J. A. Hansen, H. D. Ochs, T. H. Price, R. F. Taylor, and S. J. Klebanoff. 1984. Absence of monoclonal-antibody-defined protein complex in boy with abnormal leucocyte function. Lancet. i:535-537.

8. Hemler, M. E., C. Huang, Y. Takada, L. Schwarz, J. L. Strominger, and M. L. Clabby. 1987. Characterization of the cell surface heterodimer VLA-4 and related peptides. J. Biol. Chem. 262:1147811485.

9. Wayner, E. A., A. Garcia-Pardo, M. J. Humphries, J. A. McDonald, and W. G. Carter. 1989. Identification and characterization of the $T$ lymphocyte adhesion receptor for an alternative cell attachment domain (CS-1) in plasma fibronectin. J. Cell. Biol. 109:1321-1330.

10. Osborn, L., C. Hession, R. Tizard, C. Vassallo, S. Luhowskyj, G. Chi-Rosso, and R. Lobb. 1989. Direct expression cloning of vascular cell adhesion molecule 1 (VCAM1), a cytokine-induced endothelial protein that binds to lymphocytes. Cell. 59:1203-1211.
11. Jaffe, E. A., R. L. Nachman, C. G. Becker, and C. R. Minick. 1973. Culture of human endothelial cells derived from umbilical veins. J. Clin. Invest. 52:2745-2756.

12. Maciag, T., J. Cerundolo, S. Ilsley, P. R. Kelley, and R. Forand. 1979. An endothelial cell growth factor from bovine hypothalamus: identification and partial characterization. Proc. Natl. Acad. Sci. USA. 76:5674-5678.

13. Rothlein, R., M. L. Dustin, S. D. Marlin, and T. A. Springer. 1986. A human intercellular adhesion molecule (ICAM-1) distinct from LFA-1. J. Immunol. 137:1270-1274.

14. Gallin, J. I., R. A. Clark, and H. R. Kimball. 1973. Granulocyte chemotaxis: an improved in vitro assay employing ${ }^{51} \mathrm{Cr}$-labeled granulocytes. J. Immunol. 110:233-240.

15. Hickstein, D. D., A. Smith, W. Fisher, P. G. Beatty, B. R. Schwartz, J. M. Harlan, R. K. Root, and R. M. Locksley. 1987. Expression of leukocyte adherence-related glycoproteins during differentiation of HL-60 promyelocytic leukemia cells. J. Immunol. 138:513519.

16. Haskard, D., D. Cavender, P. Beatty, T. Springer, and M. Ziff. 1986. T lymphocyte adhesion to endothelial cells: mechanisms demonstrated by anti-FLA-1 monoclonal antibodies. J. Immunol. 137:2901-2906.

17. Dustin, M. L., R. Rothlein, A. K. Bhan, C. A. Dinarello, and T. A. Springer. 1986. Induction by IL 1 and interferon- $\gamma$ : tissue distribution, biochemistry, and function of a natural adherence molecule (ICAM-1). J. Immunol. 137:245-254.

18. Staunton, D. E., M. L. Dustin, and T. A. Springer. 1989. Functional cloning of ICAM-2, a cell adhesion ligand for LFA-1 homologous to ICAM-1. Nature (Lond.). 339:61-64.

19. Hemler, M. E. 1990. VLA Proteins in the integrin family: structures, functions, and their role on leukocytes. Annu. Rev. Immunol. 8:365-400.

20. Takada, Y., M. J. Elices, C. Crouse, and M. E. Hemler. 1989. The primary structure of the $\alpha^{4}$ subunit of VLA-4: homology to other integrins and a possible cell-cell adhesion function. $E M B O(E u r . M o l$. Biol. Organ.) J. 8:1361-1368.

21. Clayberger, C., A. M. Krensky, B. W. McIntyre, T. D. Koller, P. Parham, F. Brodsky, D. J. Linn, and E. L. Evans. 1987. Identification and characterization of two novel lymphocyte function-associated antigens, L24 and L25. J. Immunol. 138:1510-1514.

22. Groux, H., S. Huet, H. Valentin, D. Pham, and A. Bernard. 1989. Suppressor effects and cyclic AMP accumulation by the CD29 molecule of CD4 $4^{+}$lymphocytes. Nature (Lond.). 339:152-154.

23. Bednarczyk, J. L., and B. W. McIntyre. 1990. A monoclonal antibody to VLA-4 $\alpha$-chain (CDw49d) induces homotypic lymphocyte aggregation. J. Immunol. 144:777-784.

24. Elices, M. J., L. Osborn, Y. Takada, C. Crouse, S. Luhowskyj, M. E. Hemler, and R. R. Lobb. 1990. VCAM-1 on activated endothelium interacts with the leukocyte integrin VLA-4 at a site distinct from the VLA-4/fibronectin binding site. Cell 60:577-584. 